\title{
Solo, Paired, Group: A Phenomenological Dimension on the Learning Situations of STEM Students in Pre-Calculus
}

\author{
Norman Cuello Barroso ${ }^{1 *}$ (])
}

${ }^{1}$ Tanza National Comprehensive High School, PHILIPPINES

*Corresponding Author: normancuellobarroso@gmail.com

Citation: Barroso, N. C. (2020). Solo, Paired, Group: A Phenomenological Dimension on the Learning Situations of STEM Students in PreCalculus. International Journal of Pedagogical Development and Lifelong Learning, 1(2), e02007. https://doi.org/10.30935/ijpdll/8426

\begin{abstract}
Mathematics learning is one of the main goals of teaching Mathematics. Many researches have look on ways and different perspectives to improve mathematics' achievement. Among these is considering how students learn inside the class which was categorized into grouped, paired, and solo learning. These variables will be extensively discussed and research will be exhausted to provide better understanding of the research problem. This study aimed to explore the phenomenological dimensions on the learning situations of Science Technology Engineering and Mathematics (STEM) students in Pre-Calculus. Qualitative design specifically a phenomenological study was utilized in the study. Purposive sampling methodology was used and the criteria of selecting participants are one mathematically inclined, average and low performing students per section. Moreover, audio recordings of the structured interview and focus group discussions were utilized as basis in thematic analysis of the study. Self, paired and group study revealed as the learning situations and strategies of grade 11 STEM students in Pre-Calculus. The practices of STEM students in learning Pre-Calculus are use of online resources, review lectures, study with friend, paired with intelligent student or low performing student, and listen, share and facilitate group study. The themes emerged on the experiences of STEM students in studying Pre-Calculus are lack of comprehension, clarified solutions and inability to raise queries for low performing students; learn alternative solutions, interchange ideas and raise questions for average students; and share ideas and facilitate teaching and learning for mathematically inclined students. The study is limited on the after-class learning extension activities of the participants of the study on three learning strategies in which it ensured diverse learning strategy that could possibly lead to different learning successes of students.
\end{abstract}

Keywords: learning situations, self-study, paired-study, group study

Received: 22 May 2020 • Accepted: 28 Jun. 2020

\section{INTRODUCTION}

Philippine educational system under the "Enhanced Basic Education Act of 2013 (Republic Act No. 10533)" envisions to strengthen the curriculum and increasing the number of years for basic education (Chan, 2019). Global competitiveness was a major reason why the program is deemed to be essential for the growth of the country (Chua, 2015). In order to be concurrent with the international educational trend therefore the additional two more years in high school which is called senior high school program leads on developing 21st century learners ready for college, entrepreneurship and technicalvocational skills. In connection, Science Technology Engineering and Mathematics (STEM) is one of the strands under academic track in senior high which trained students to be equipped with different concepts in Mathematics and Science as preparation for students who will take engineering and medical-related courses. The specializations under this strand are Pre-Calculus, Basic Calculus, General Physics 1 and 2, General Biology 1 and 2, and General Chemistry 1 and 2. Among these disciplines, Pre-Calculus is considered to be the fundamental subject in STEM since it is a prerequisite subject before students can enroll in Basic Calculus and General Physics I. Impliedly, mathematics learning is an essential component for the success of STEM students.

Teachers play a significant role in enhancing confidence of students in doing mathematics (Furner, 2017). It implies that teachers should be creative in providing necessary interventions that could probably develop the mathematics skills of the students. Moreover, STEM education was a systematic teaching and/or learning process in the STEM fields (Kocabas et al., 2020). According to Kocabas et. al. (2020) as cited by Becker and Park (2011) that STEM education aims to improve students' science and mathematics scores and prepare them for their future education and careers. Focusing on improving performance of STEM students in mathematics and science is the main goal of STEM education for them to be prepared on their future professions. To meet this goal, there should be integration of STEM learning activities that could increase STEM interests and experiences. (Staus et.al 2020, Siregar et.al. 2020). However, the learning activities should match the attitude, interest and preferred ways of learning of STEM students. In connection, to increase the mathematics achievement of each STEM 
student, it is essential to classify them into mathematically inclined, average and low performing students. In this study, it will highlight the lived experiences of each type of STEM learner in terms of their learning preferences in Pre-Calculus. Therefore, STEM mathematics teacher can utilize this as basis in providing interventions and different learning activities for each type of STEM learner.

Furthermore, learning Mathematics deals on developing students' wholesome attitudes and positive beliefs in the discipline (Mathematics Framework, 2011). In connection, the senior high school mathematics curriculum guides also highlight the need for students to learn and explore mathematics comprehensively (Jaudinez, 2019). It addressed the significant value of inspiring and motivating students to enjoy learning mathematics. Positive attitudes of STEM students could possibly be a springboard into a successful result of assessment of the students. However, the common problems on the mathematics curriculum in the senior high school program are weak foundation in Mathematics, lack of enthusiasm of students in learning Mathematics, and huge gap on the mathematical abilities of the students (Chua, 2019; Jaudinez, 2019). These problems challenged mathematics teachers on the possible strategies, techniques and interventions on how to finish the required learning competencies in the curriculum guide, to turn students' perspective into more optimistic view and to facilitate an effective mathematics learning. As cited on the $\mathrm{K}$ to 12 mathematics curriculum framework, teachers could encourage learners to study alone and look for a partner or a group to work collaboratively in answering numerous mathematics problems.

Critical thinking and problem-solving skills are twin goals of the $\mathrm{K}$ to 12 mathematics curriculum framework. The development of these essential cognitive skills inspires the teacher in Pre-Calculus to start stimulating the interests and attitudes of the STEM students in Mathematics. Further, Jaudinez (2019) stated that the utilization of online platforms like watching youtube, encouraging group work, mentoring with peers among students of Calculus can enhance a 21stcentury skill where students should be equipped with. In connection, self-study (solo), paired-study and group study are evident learning situations among STEM students in Pre-Calculus.

Self-regulated learning refers to personal goal of using their cognitive and behavioral skills in order to understand concepts of specific discipline (Rovers, 2018). Independent study or self-study has in connection with self-regulated learning in which it refers to students who wanted to study alone. Students are allowing themselves to study in a quiet place or sometimes they wanted to study while listening with the music. On the other hand, paired study is an alternative way of students in guiding each other towards leaning (Topping et al., 2013). Reciprocal and fixed tutoring are two classification of paired study (Thurnston et al., 2007). Fixed tutoring is when the low performing students (tutee) are partnered with intelligent students (tutor) while reciprocal tutoring refers to both students experienced to be a tutor and a tutee. It implies that in fixed tutoring there is sharing of ideas from the intelligent students while in reciprocal tutoring there is interchanging of ideas. Moreover, group study in mathematics allow learners to comprehend problems in a better way and learn the discipline by applying what they understand instead of memorizing the concepts (Kocak et al., 2009). Learning with group or known as cooperative learning is an effective strategy in mathematics as revealed on different studies. It allows learners to study with their groupmates and practice brainstorming session and sharing of ideas. Most of the literatures and studies focused on a quantitative view of self-study, paired study and group study while some of the researches focused on just one learning preference style. Therefore, this study will be dealing on learning situations of STEM students in Pre-Calculus which are selfstudy, paired study and group study in a qualitative view.

This study aims to (1) describe the the learning situations and learning strategies of the grade 11 STEM students in Pre-Calculus, (2) describe the Pre-Calculus learning strategy of low performing students, average students and mathematically inclined students, and (3) determine how the learners attributed learning strategy to their performance in Pre-Calculus.

\section{LITERATURE REVIEW}

Mathematics learning is one of the main goals of teaching Mathematics. Many researches have look on ways and different perspectives to improve mathematics' achievement. Among these is considering how students learn inside the class which was categorized into grouped, paired, and solo learning. These variables will be extensively discussed and research will be exhausted to provide better understanding of the research problem.

\section{Solo Study}

Solo study, self-study or self-regulated learning refers to the study of oneself, one's thinking and actions without relying on others (Khairudin et al., 2020). Self-regulated learning underlines the importance of autonomy and personal responsibility in learning activities (Sutrisno, 2020).

Sutrisnno (2020) found out that self-regulated learning has positive effect on the intelligence quotient and mathematical disposition of the students.

However, Rameli et al. (2016) cited that one of the challenges of students in learning mathematics is low self-regulation wherein students have difficulty in doing math exercises and lack of motivation.

\section{Paired Study}

Besides grouping students, one-way students could also learn is through paired learning. It is a cooperative learning approach in which students are paired with another student.

Peer tutoring creates an opportunity for the students to utilize their knowledge and experience in a meaningful way. In this process the tutors reinforce their own learning through reviewing and reformulating their knowledge. (Ali et al., 2015).

Abdulkarim R. (2016) cited that peer teaching is an essential learning strategy that can increase mathematics achievement of the students. It was also supported by Alegre et al. (2019) that peer tutoring can elevate academic results of secondary students in Mathematics.

Boz Yaman (2019) found three successful combinations of paired study. One of the successful dyads presented purely tutoring, while another presented scaffolding, and the most successful dyad displayed reciprocal peer tutoring with scaffolding.

Moreover, according to Clark (2012) as cited by Stearns (1999), group of researchers found that by working together, children learned to listen to the teacher and to each other in a way that was self-edifying. Students shared ideas and encouraged each other's efforts. 
These researches affirm that cooperative learning is not only for students grouped into 3 or more but also by pair. It showed significant increase in learning since students feel that with a partner, they could share their ideas and could get ideas in return.

\section{Group Study}

Being in a group while studying has been widely known to be an effective form of learning. Though many researchers reported this, it is still argumentative to say that this is the best learning for students.

Sofroniou et al. (2016) found out that students who struggle in mathematics became discouraged with individual work and they feel less stress when they are group with their classmates.

Emilda (2015) revealed that the students' achievement of Mathematics was better $78.50 \%$ passed by applying integrated brain gym in pair checks of cooperative learning. Brain Gym is a movement which could be done in order to help students equalize their left brain and right brain.

In addition, Cen et al. (2014) on their case study indicated that group learning with efficient collaboration patterns improves students performance comparing to learning alone.

Finally, Gokce (2011) discovered that most of the teachers benefit from group studies techniques effectively, and students are satisfied with the group studies but every student cannot attend the group studies and learn, so some of the students prefer individual studies.

Discussing these researches resulted to the conclusion that students being in a group have a lot of advantages. On the other hand, teachers often struggle with this instructional method because one member of the group may do most of the learning tasks while other students are "along for the ride." Hence, many factors should also be considered on how to distribute tasks to students for them not to be confused and ashamed of their role in the team. To ensure that students are on task and taking a share of the workload, each student must have a task at hand. Also, each student must share personal accountability and responsibility for the success of the group in order to make a group truly cooperative.

\section{Synthesis}

Most of the researches revealed that students learned more significantly by group than by doing it by partner or alone. But the fact cannot be denied that not all are comfortable studying with group. To fulfil this gap, this research will describe the learning techniques of STEM students in Pre-Calculus class to suggest strategies fit for all learners learning through solo, paired or group scenario. This is will ensure diverse learning strategy that could possibly lead to different learning successes of students.

\section{METHODOLOGY}

This study utilized a qualitative design specifically a phenomenological study. As cited by Groenewald (2004) that phenomenological research was first introduced by a German philosopher Edmund Husserl. This study is concentrated on identifying phenomena and lived experiences of the participants of the study on their learning strategies in Pre-Calculus.

\section{Sampling}

This study based on the sampling method used a purposive sampling methodology. A purposive sampling is a non-probability sample that is selected based on characteristics of a population and the objective of the study (Crossman, 2018). Particularly, criteria are used in this study wherein there are specific criteria in selecting the participants. The sample criteria are based on the selection of grade 11 STEM students at TNCHS. The first criterion is one mathematically inclined student per section. Since there are three grade 11 STEM sections therefore there are 3 mathematically inclined students who participated in the study. The mathematically inclined student is selected based on the highest average grade on the first grading period in Pre-Calculus. The second and third criteria are one average student and one low performing student per section. There is a total of 3 average students and 3 low performing students who participated in the study. The average student is selected using the median while the low performing student is selected based on the lowest grade in the 1st grading period in Pre-Calculus. The sample size of 3 mathematically inclined students, 3 average students and 3 low performing students are the initial sample size and the final sample size is determined by the saturation of data.

\section{Data Collection}

Two types of qualitative data are collected for this study; the audio recordings of the structured interview and focus group discussions, and memoing.

There are three sessions of interview for the participants of the study. The structure interview attached in Appendix $\mathrm{C}$ and audiotaped are utilized for the interview sessions. The interview guide questions focused on the lived experiences of the participants on their learning strategies in Pre-Calculus. The participants of the study are interviewed on three different schedules. The researcher allotted 1 day per section so that he can get all the salient points on the interview sessions of the participants of the study. Focus group discussion is facilitated by the researcher due to some ambiguous answers on the interview session. This was utilized for the clarifications and to finalize the answers on the interview of the participants of the study.

Memoing is the researcher's field notes recording what the researcher hears, sees, experiences and thinks in the course of collecting and reflecting on the process (Groenewald, 2004). This study used memoing so that the researcher records the sensitive information during the interview such as the classroom environment and individual reactions of the participants of the study.

\section{Data Analysis}

This study used the simplified version of Hycner's (1999) five steps or phases of explicitation process. The type of coding that the researcher utilized is an nvivo coding.

Bracketing and phenomenological reduction - in this process, the researcher listened repeatedly to the audio recording on the interview to the participants. This emphasized the unique own unique experiences of the participants on their learning strategies in PreCalculus.

Delineating units of meaning - as cited by Groenewald (2004) that in this process the list of units of relevant meaning extracted from each interview is carefully scrutinized and the clearly redundant units are 
Table 1. Learning Strategies of STEM Students in Pre-Calculus

\begin{tabular}{ll}
\hline Themes & Core Ideas \\
\hline Self-Study & Use of online resources, review examples, stay in quiet place \\
\hline Paired-Study & Peer tutoring, shows cooperation, interchange ideas, \\
\hline Group Study & Online group study, shows cooperation, familiarity on the solutions, face-to- face discussion \\
\hline
\end{tabular}

Table 2. Challenges Experienced in Doing the Learning Strategies of STEM Students in Pre-Calculus

\begin{tabular}{ll}
\hline Themes & Core Ideas \\
\hline Self-Study & Difficulty in understanding the concepts, lack of comprehension \\
\hline Paired-Study & Inability to socialize, limited resources \\
\hline Group Study & Boredom, inability to entertain all questions, internet connection \\
\hline
\end{tabular}

eliminated. In this phase, the researcher gets the most salient points on the interview to the participants.

Clustering of units of meaning to form themes - In this phase, the researcher clusters the most salient points on the interview based on the different emerging themes.

Summarize each interview - In this phase, the researcher validates, checks and modifies all the emerging themes.

General and unique themes for all interviews and composite summary - the researcher looks on the common themes. After this, the researcher generalizes the common themes through the analyzation and answering the research questions.

\section{RESULTS}

Learning Situations and Strategies of STEM Studen ts in PreCalculus

STEM Students have different ways and strategies on how they will cope-up with the difficulties that they may encounter in studying PreCalculus. Surviving in numerous formative and summative assessments is one of the greatest achievements to every student under STEM strand.

Table 1 shows the learning strategies of STEM students in PreCalculus. It can be gleaned from the table that the learning situations and strategies of grade 11 STEM students in Pre-Calculus are self-study (solo), paired-study and group study. In doing self-study, students are using online resources like watching youtube and searching lectures on google, review examples taught by the teacher and stay in quiet place. Some of the students preferred to do paired-study in which they can show cooperation and interchange ideas while doing peer tutoring. In this strategy, students are paired with friends and most of the time low performing students are partnered with mathematically inclined students. Group study is also one of the learning strategies of STEM students wherein they can do this on a face-to-face discussion while some of the groups use online platforms like zoom app and video chat ( $\mathrm{fb}$ messenger). This strategy leads in showing cooperation among the members of the group and it allows each student to familiarize themselves with the steps and solutions of any problem.

"Some of my intelligent classmates are doing self-study. They are advanced in the lesson since they do a lot of readings on the internet and they also watch videos on the youtube" (Student 3)

"Based on my observation, my classmates are looking for a partner in studying lessons in Pre-Calculus. They are helping each other by sharing their own expertise. (Student 2)

"In our room, most of my classmates are attending group study facilitated by the leader. We are doing this after the class. Sometimes our leader also gives us different examples in our group chat in facebook then we need to answer that on our own then after a minute he will reveal the solutions to the problem." (Student 8)

Table 2 illustrates the challenges experienced by the STEM students in doing the different learning strategies. Difficulty in understanding the concepts and lack of comprehension of the students are challenges in doing self-study. Students have the ability to answer examples in Pre-Calculus but they are hesitant on their own solutions and final answers. Even watching videos and reading lectures on internet are not effective to some students because of their difficulty in understanding basic concepts in Pre-Calculus. On the other hand, problems arise in paired study because of the inability of the students to socialize to other classmates and due to limited resources. Partners may only utilize lectures as basis of their studying but familiarity on the solutions affect the low scores on the assessment of the students. Moreover, numerous members may lead on inability of the leaders to entertain all questions of the members which can turn also into boredom. Since some of the group is doing online group study therefore barriers happened due to slow internet connection while some of the students don't have financial support for data connection.

"Oftentimes, group study turns into boredom since leaders failed to entertain some of the questions of my classmates." (Student 6)

Learning Strategies of Low Performing STEM Students in PreCalculus

Figure 1 shows the practices of low performing STEM students in studying lessons in Pre-Calculus. In order to understand the concepts taught by the teacher in Pre-Calculus, low performing students are using online resources like watching youtube, reviewing lectures taught by the teacher, studying lessons with a partner and attend and listen on the facilitated group study by the leader. Among these, the most frequent practice of low performing STEM students is looking for a partner who is intelligent and easy to be with.

Table 3 explains the experiences of low performing STEM students in studying lessons in Pre-Calculus. It can be gleaned on the table that self-study is not their preferred learning strategy because of lack of comprehension in understanding concepts in Pre-Calculus. Though there are numerous times that they tried to review illustrative examples of the teacher, search techniques in internet or watch videos in youtube, however they find it difficult to study alone because they don't have opportunity to ask some clarifications on the topic. Likewise, most of the times they participated on group study as listener but some of their queries and questions are not clarified and answered due to time constraints and numerous students who are asking for clarifications. Hence, paired study reveals as their preferred learning strategy because they have the chance to share misconceptions and listen on the explanations of their partner. In this strategy, steps and solutions are properly taught to them. 


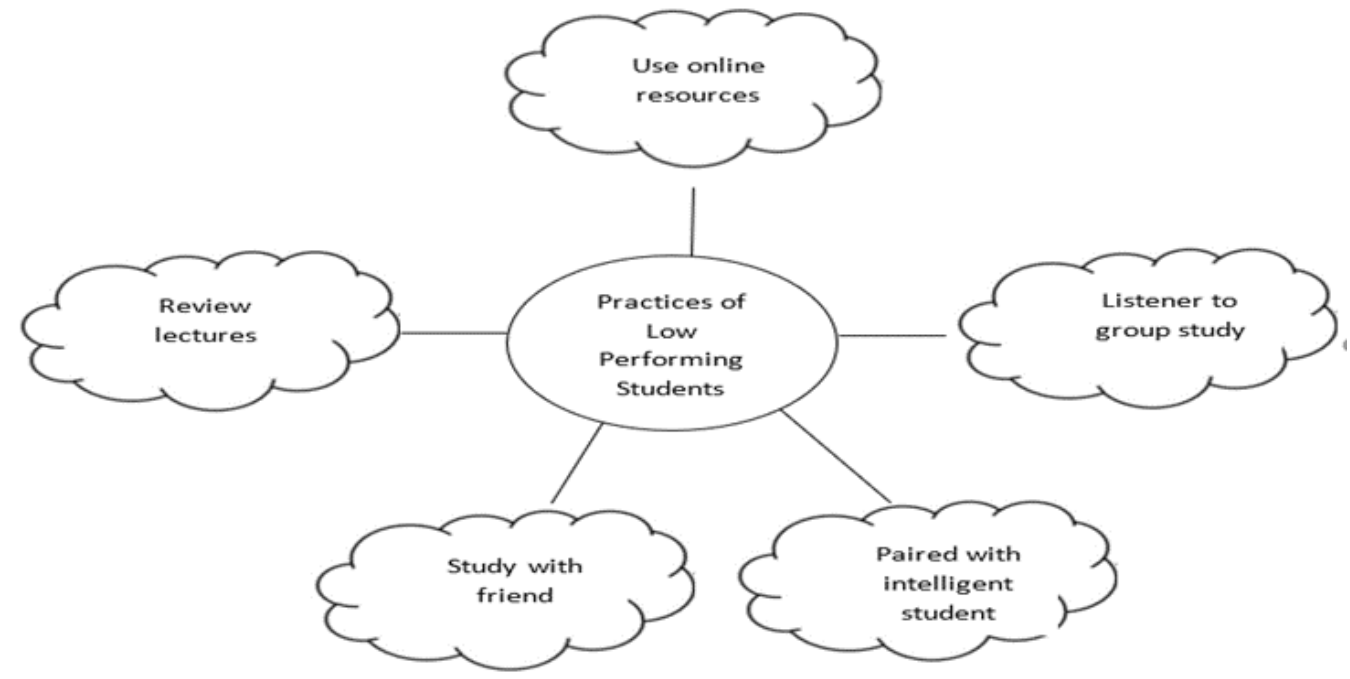

Figure 1. Practices of Low Performing STEM students in Learning Pre-Calculus

Table 3. Experiences of Low Performing STEM Students in Learning Pre-Calculus

\begin{tabular}{ll}
\hline Themes & Core Ideas \\
\hline Lack of Comprehension & hesitant in final answer, difficulty in coping up with solutions \\
\hline Clarified Solutions & shared misconceptions on the topic, listened on the explanations of partner \\
\hline Inability to raise queries & Shy of asking questions, listen on the discussion of leaders \\
\hline
\end{tabular}

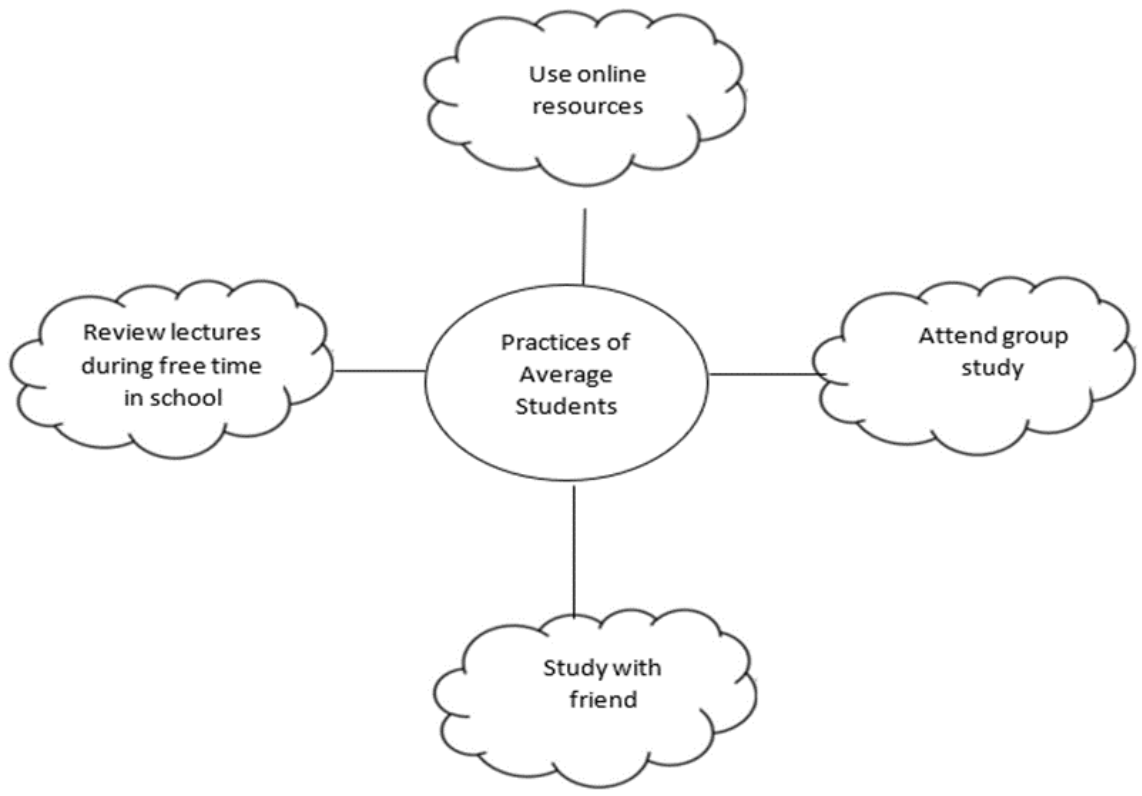

Figure 2. Practices of Average STEM students in Learning Pre-Calculus

"I am doing self-study at home wherein I am trying to answer examples taught by our teacher. However, I am hesitant on my final answer that's why I am searching some examples on the internet but I failed to understand the explanations." (Student 1)

\section{Learning Strategies of Average STEM Students in Pre-Calculus}

Figure 2 shows the practices of average STEM students in studying lessons in Pre-Calculus. Use of online resources like studying solutions, process and techniques of specific problem in the internet and reviewing examples by answering the same problem without looking on lecture notebooks are the common practices of average STEM students in learning numerous concepts in Pre-Calculus. Sometimes looking for a friend to study with and attending a group study are the strategies of average students just to cope up with difficult lessons in Pre-Calculus.

Table 4 explains the experiences of average STEM students in studying lessons in Pre-Calculus. Studying alone enables the average students to learn alternative solutions because it helps them figuring out the different concepts in Pre-Calculus. Hence, utilizing online platforms like google in searching some examples or practice exercise leads on challenging each learner on understanding difficult concepts. Furthermore, interchanging ideas happened when the students are partnered with a friend. In this situation, both students are sharing ways and solutions on how to easily understand different concepts in PreCalculus. It also shows rapid progress of learning that results to high 
Table 4. Experiences of Average STEM Students in Learning Pre-Calculus

\begin{tabular}{ll}
\hline Themes & Core Ideas \\
\hline Learn Alternative Solutions & learned techniques, answer math problems/exercises, \\
\hline Interchange ideas & interchanged ways in solving problems, asked difficult questions \\
\hline Raise queries & asking questions need to be clarified \\
\hline
\end{tabular}

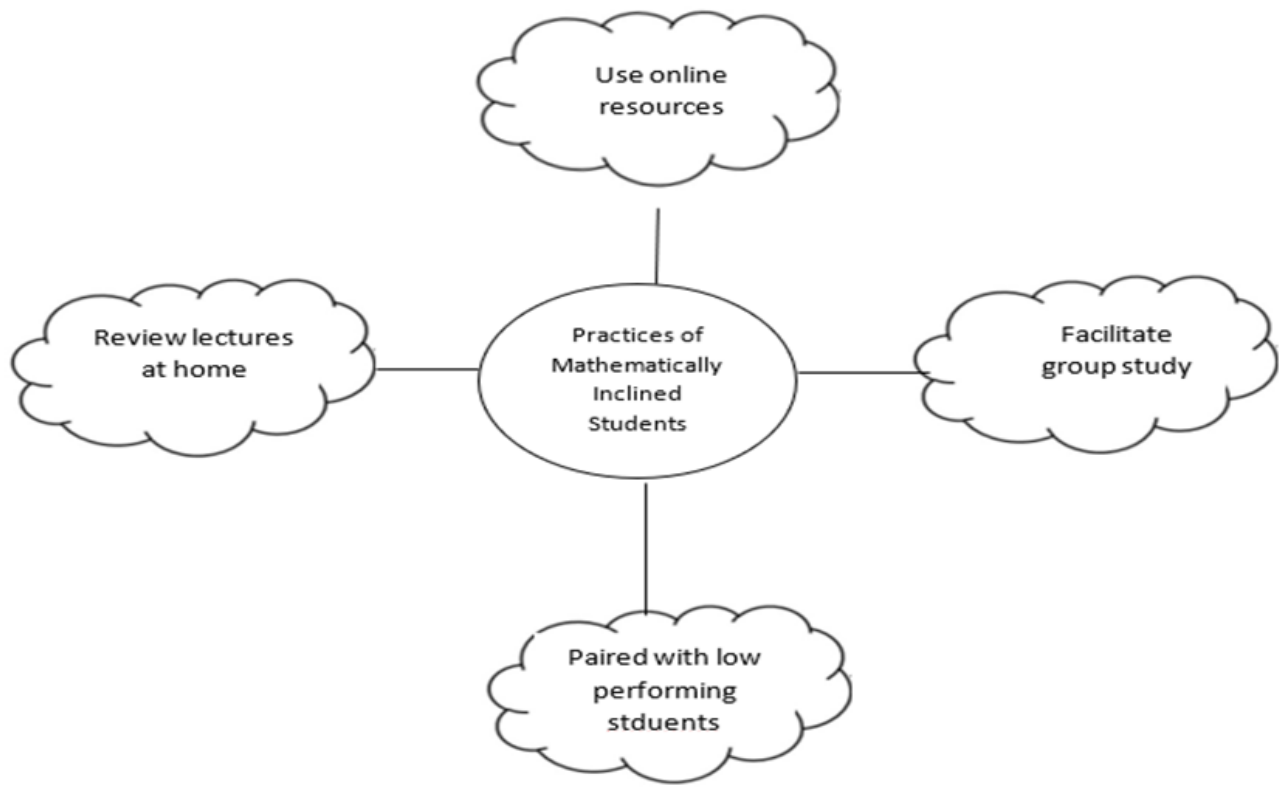

Figure 3. Practices of Mathematically Inclined STEM students in Learning Pre-Calculus

Table 5. Experiences of Mathematically Inclined STEM Students in Learning Pre-Calculus

\begin{tabular}{ll}
\hline Themes & Core Ideas \\
\hline Learn Alternative Solutions & learned techniques, answer challenging math problems \\
\hline Share ideas & Clarify misconceptions of the partner, show steps and process to the partner, give another problems/ example \\
\hline Facilitate teaching and learning & Entertain questions, show steps and solutions, check the answers of the classmates/groupmates \\
\hline
\end{tabular}

scores in examination. In group study, learners are given opportunity to ask questions. It allows students to learn from others answered queries and questions of the facilitators.

I preferred to do self-study because I was able to figure out my own strengths and weaknesses. And if there are parts that I find difficult then I am reading books, searching on internet or watch educational videos in youtube so that I would be able to understand the concept."(Student 5)

Learning Strategies of Mathematically Inclined STEM Students in Pre-Calculus

Figure 3 illustrates the practices of mathematically inclined STEM students in studying lessons in Pre-Calculus. Likewise, on the practices of average students, mathematically inclined students also utilized online platforms like watching videos in youtube and reading numerous mathematics techniques in the internet. Most of the time, they are partnered with low performing students and they facilitate group study so that they can guide and teach their classmates or groupmates who are in need of help.

Table 5 explains the experiences of mathematically inclined students in studying lessons in Pre-Calculus. These students shared that studying alone gives them opportunity to strategize their own learning style and habits. It leads on learning different techniques and short cuts on how to solve challenging questions in Pre-Calculus. Moreover, mathematically inclined students also experienced to be partnered with low performing students wherein they are tasked to clarify misconceptions of the partner and show easiest way on how to solve problems. However, since there are at most 3 low performing members in the group that is why the leaders preferred to facilitate group study. In this learning strategy, leaders are entertaining questions, showing steps and solutions and checking answers of the groupmates. Though mathematically inclined students are honest that there are questions that they failed to answer but this leads them to search for the possible answers on the different queries of the members in the group.

"I preferred to do group study because even I am teaching them on different concepts in Pre-Calculus still there are instances wherein some of my groupmates are sharing easiest way on how to solve problem. In this scenario, I can say that they've learned a lot from me but I also learned from them." (Student 7)

\section{Attribute of Learning Strategies to the Performance of STEM Studen ts in Pre-Calculus}

Figure 4 shows that solo, paired and group learning strategies helped learners in improving performance in Pre-Calculus. This was evident in the results of summative assessments and the active participation of the students during the discussion proper. It develops confidence and reduces anxiety level of low performing students in Mathematics. Through the help of these learning strategies, some of the STEM students were able to realize the significant value of studying Pre-Calculus and the interesting side of this subject. It also leads in increasing socialization and establishing rapport of STEM students by helping each other and sharing technique with other students. During the focus group discussion, the teacher expressed his happiness in 


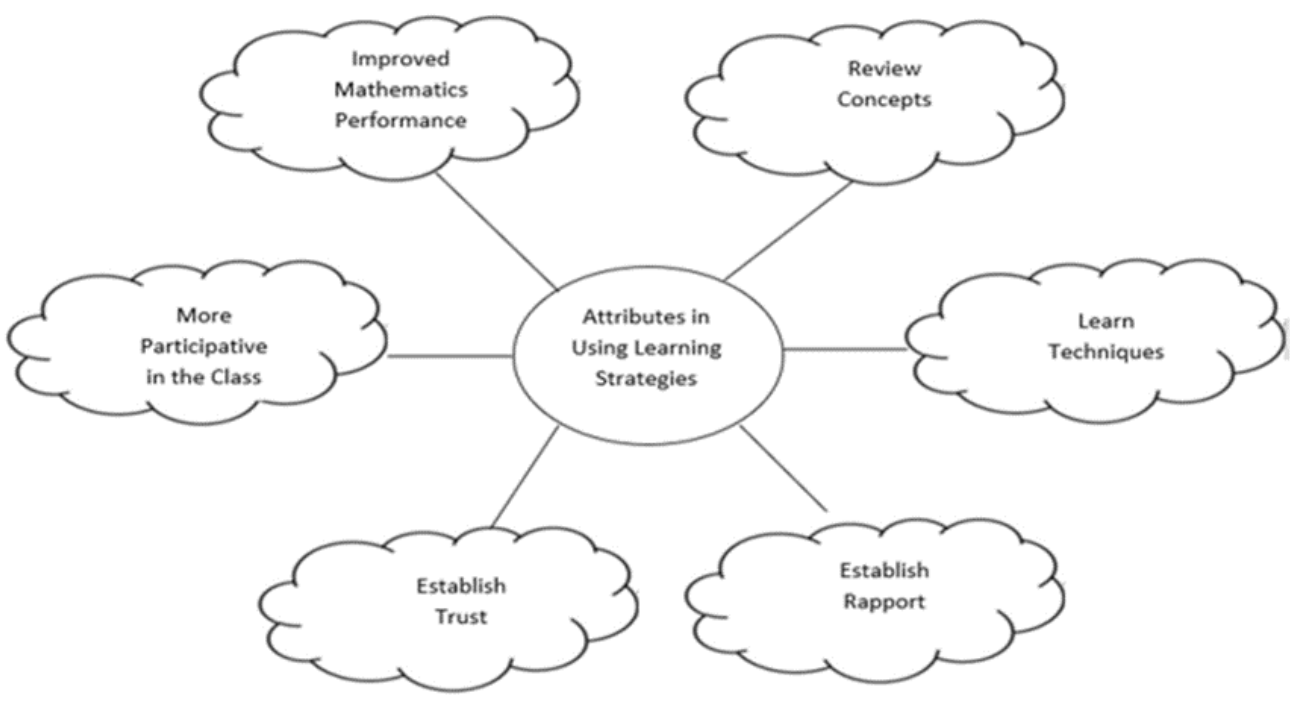

Figure 4. Attributes of Using Learning Strategies to the Performance of STEM Students in Pre-Calculus

witnessing the effort of STEM students in doing these three learning strategies. He cited that instead of facilitating a remedial session or providing intervention, the students specifically the leaders have then initiative to do paired-study and group- study.

"From these learning strategies, I improved a lot in Mathematics and I've learned how to establish rapport with my classmates. I am now active when there is recitation during the discussion of our teacher in Pre-Calculus." (Student 8)

\section{DISCUSSION}

The learning situations and strategies of grade 11 STEM students in Pre-Calculus are self-study (solo), paired-study and group study. Searching on internet and watching videos in youtube are some of the techniques of the students in studying alone at home. During free time or after class, students utilized lecture notes and examples of the teacher in reviewing lessons in Pre-Calculus. This prevails as one of the routinely study habits of average and mathematically inclined students. It gives the students the opportunity to strategize their own learning style and habits. Impliedly, self-study has a positive effect in intelligence quotient and mathematical disposition of the students (Sutrisno, 2020). However, low performing students and some average students did not prefer this learning strategy because on lacking of comprehension and understanding on difficult concepts in Pre-Calculus. Extending time and effort in studying lessons in Pre-Calculus contributed a little amount of learning compared when they attended group study or paired with other students. It was supported by the study of Rameli et. al 2016 that one of the challenges of students in learning mathematics is low self-regulation wherein students have difficulty in doing math exercises and lack of motivation.

There are two ways on how STEM students did paired study. The first one is when the low performing students are partnered with mathematically inclined students. Most of the time partnered students extended time just to review lessons in Pre-Calculus. The sessions happened twice a week depending upon the availability of both partners. Mathematically inclined students explained lessons specifically those complicated concepts in Pre-Calculus to the low performing students. With this, STEM students were able to establish rapport to each other and an opportunity to clarify misconceptions in Pre-Calculus. It helps in improving the mathematics performance of low performing students. The second is students are paired with their close friends. It allows both students to share expertise and techniques to each other. With this way, students are not afraid of asking questions from their partner and it gives them the chance to help each other in improving their performance in Pre-Calculus.

Leaders usually facilitated group study after class and sometimes due to time constraints, some of the groups are doing online group study. However, there are students who are not attending group study because they preferred to study at home. This learning strategy allows other students to ask questions and suggest solutions but due to time constraints, not all the questions and queries of the students are being answered and clarified. With this, online group study is another way of studying with a group. Each group has group chat in facebook and group study happened when the leader or one of the members of the group is sharing questions in Pre-Calculus. It motivates each member to participate in this online group study by answering the questions raised by the leader and share solutions at the same time. In a focus group discussion with the teacher and students, it reveals that group study helps students increased performance in Pre-Calculus. Those low performing students who failed to attend group study got lowest score but there are low performing students who attended group study sessions and the substantial increase of their performance was highly evident. Consequently, Cen, et.al (2014) indicated that group learning with efficient collaboration patterns improves students' performance comparing to learning alone. It implies a diverse learning strategy of STEM students but during the focus group discussion, group study was highlighted as an effective learning strategy that helps learner in enhancing their skills and knowledge in Pre-Calculus.

Low performing students in Pre-Calculus experienced doing selfstudy, paired-study and group study. In terms of self-study, they did not prefer this strategy because of lack of comprehension in understanding concepts in Pre-Calculus. Likewise, most of the times they participated on group study but some of their queries and questions are not clarified and answered due to time constraints and numerous students who are 
asking for clarifications. In addition, paired-study is the most preferred learning strategy of low performing students. It is focus-oriented learning strategy for them since the mathematically inclined students explained all their misconceptions in Pre-calculus. There is focus on specific topics and they can easily ask questions to their partners. It was supported by the study of Clark (2012) that through paired-learning strategy students can increase their academic performance because they could share their ideas and could get ideas in return.

Studying alone helps average STEM students in figuring out the different concepts in Pre-Calculus that they find difficult. Through this, performance in Pre-Calculus can be improved without the help of others. Moreover, in doing paired-study, average students are partnered with a friend in Pre-Calculus because it shows give-and-take relationship. It was supported by the study Alegre et al. (2019) and Abdulkarim R. (2016) that peer teaching is an essential learning strategy that can increase mathematics achievement of the students. On the other hand, group study gives the average students the opportunity to ask questions. Cen, et.al (2014) supports this argument that on his case study it indicates that group learning with efficient collaboration patterns improves students' performance comparing to learning alone.

Sharing expertise to others and facilitating a group study is a worthwhile contribution of mathematically inclined students for the progress of the performance in Pre-Calculus of STEM students. Group study encouraged learners to ask questions about complex-related mathematics problems. With this, mathematically inclined students saw the collaborations of their classmates. They facilitated group study after class and most of their classmates are participating each session of group study because it improves their performance in Pre-Calculus. However, there are some students who did not prefer attending a group study because they prefer to study alone. It implies that students who are participating in group study are composed of students who have difficulty understanding the concepts in Pre-Calculus and leaders or mathematically inclined students who facilitated the group study. It was supported by the study of Gokce (2011) who discovered that most of the teachers benefit from group studies techniques effectively, and students are satisfied with the group studies but every student cannot attend the group studies and learn, so some of the students prefer individual studies.

\section{REFERENCES}

Abdelkarim, R., \& Abuiyada, R. (2016). The Effect of Peer Teaching on Mathematics Academic Achievement of the Undergraduate Students in Oman. International Education Studies, 9(5), 124. https://doi.org/10.5539/ies.v9n5p124

Alegre, F., Moliner, L., Maroto, A., \& Lorenzo-Valentin, G. (2019). Peer tutoring and mathematics in secondary education: literature review, effect sizes, moderators, and implications for practice. Heliyon, 5(9), e02491. https://doi.org/10.1016/j.heliyon.2019. e02491

Ali, N., Anwer, M., \& Jaffar, A. (2015). Impact of Peer Tutoring on Learning of Students. Journal for Studies in Management and Planning, 1(2), 61-66. Available at SSRN: https://ssrn.com/abstract=2599095
Boz Yaman, B. (2017). A multiple case study: What happens in peer tutoring of calculus studies?. International Journal Of Education In Mathematics, Science And Technology, 7(1), 53-72. https://doi.org/ 10.18404/ijemst.328336

Cen, L., Ruta, D., Powell, L., \& Ng, J. (2014, Dec.). Learning alone or in a group \&\#x2014; An empirical case study of the collaborative learning patterns and their impact on student grades. 2014 International Conference on Interactive Collaborative Learning (ICL), Dubai, United Arab Emirates. https://doi.org/10.1109/ ICL.2014.7017845

Chua, V. C. G. (2015). Assessment of the Mathematics curriculum in the SHS modelling program. https://doi.org/10.13140/RG.2.1.2340.7849

Clark, E. A. (2012). Pairing and comparing in the middle school Mathematics classroom (Master's Thesis, Education and Human Development), Department of Education, State University of New York College at Brockport. Retrieved from http://digitalcommons.brockport.edu/ ehd_theses $/ 133$ ? utm_source=digitalcommons.brockport.edu\% $2 \mathrm{Fe}$ hd_theses\%2F133\&utm_medium=PDF\&utm_campaign=PDFCov erPages

Crossman, A. (2018). Understanding purposive sampling: An overview of the method and its applications. ThoughtCo. Retrieved on 16 March 2019 from https://www.thoughtco.com/purposivesampling-3026727

Emilda. (2015). Teaching Mathematics through integrated brain gym in pair checks of cooperative learning. IOSR Journal of Humanities and Social Science (IOSR-JHSS), 20(11), 27-31. https://doi.org/10.9790/0837-201132731

Furner, J. M. (2017). Helping all Students Become Einstein's using Bibliotherapy when Teaching Mathematics to Prepare Students for a STEM World. Pedagogical Research, 2(1), 01. https://doi.org/10.20897/pedre.201701

Gökçe, E. (2011). The influence of group studies techniques upon teaching \& learning process in elementary education. Procedia Social and Behavioral Sciences, 15, 3947-3956. https://doi.org/10.1016/j.sbspro.2011.04.399

Groenewald, T. (2004). A phenomenological research design illustrated. International Journal of Qualitative Methods, 3(1), 42 - 55. https://doi.org/10.1177/160940690400300104

Hycner, R. H. (1999). Some guidelines for the phenomenological analysis of interview data. Qualitative Research, 8(3), 279-303. https://doi.org/10.1007/BF00142995

Jaudinez, A. S. (2019). Teaching senior high school mathematics: problems and interventions. Pedagogical Research, 4(2), em0031, https://doi.org/10.29333/pr/5779

Khairudin, Suryani, K., Fauzan, A., \& Armiati. (2020). Self Regulated Learning of Mathematics Education Students of Bung Hatta University. Journal of Physics: Conference Series, 1429, 012003. https://doi.org/10.1088/1742-6596/1429/1/012003

Kocabas, S., Ozfidan, B., \& Burlbaw, L. M. (2020). American STEM Education in Its Global, National, and Linguistic Contexts. Eurasia Journal of Mathematics, Science and Technology Education, 16(1), em1810. https://doi.org/10.29333/ejmste/108618

Koçak, Z. F., Bozan, R., \& Işı1k, Ö. (2009). The importance of group work in mathematics. Procedia - Social and Behavioral Sciences, 1(1), 2363-2365. https://doi.org/10.1016/j.sbspro.2009.01.414 
Mohd Rameli, M. R. (2016). Challenges in Mathematics Learning: A Study from School Student's Perspective. In A. Khan, M. N. A. Ghafar, A. R. Hamdan, \& R. Ralib (eds.), Research on Educational Studies - Volume 1. New Delhi, India: Vedams eBooks (P) Ltd.

Rovers, S. F. E., Stalmeijer, R. E., van Merrienboer, J. J. G., Savelberg, H. H. C. M., \& de Bruin, A. B. H. (2018). How and why do students use learning strategies and desirable difficulties with effective strategy users. Front Psychology, 9, 2501. https://doi.org/10.3389/ fpsyg.2018.02501

SEI-DOST \& MATHTED, (2011). Mathematics framework for Philippine basic education. Manila: SEI-DOST \& MATHTED.

Siregar, N. C., Rosli, R., Maat, S. M., \& Capraro, M. M. (2020). The Effect of Science, Technology, Engineering and Mathematics (STEM) Program on Students' Achievement in Mathematics: A Meta-Analysis. International Electronic Journal of Mathematics Education, 15(1), em0549. https://doi.org/10.29333/iejme/5885

Sofroniou, A., \& Poutos, K. (2016). Investigating the Effectiveness of Group Work in Mathematics. Education Sciences, 6(4), 30. https://doi.org/10.3390/educsci6030030
Staus, N. L., Falk, J. H., Penuel, W., Dierking, L., Wyld, J., \& Bailey, D. (2020). Interested, Disinterested, or Neutral: Exploring STEM Interest Profiles and Pathways in A Low-Income Urban Community. Eurasia Journal of Mathematics, Science and Technology Education, 16(6), em1853. https://doi.org/10.29333/ejmste/7927

Sutrisno AB, J. (2020). Self-regulated learning: Intelligence quotient and mathematical disposition. Journal of Physics: Conference Series, 1422, 012020. https://doi.org/10.1088/1742-6596/1422/1/012020

Thurston, A., \& Topping, K. (2007). Peer Tutoring in Schools: Cognitive Models and Organizational Typography. Journal of Cognitive Education and Psychology, 6(3), 356-372. https://doi.org/10.1891/194589507787382070

Topping, K., Dehkinet, R., Blanch, S., Corcelles, M., \& Duran, D. (2013). Paradoxical effects of feedback in international online reciprocal peer tutoring. Computers \& Education, 61, 225-231. https://doi.org/10.1016/j.compedu.2012.10.002 